\title{
System Diagnostics of Supporting-Rod Porcelain Insulation at Digital Substations
}

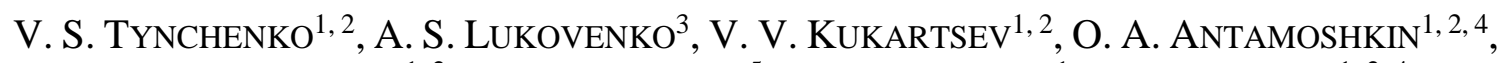 \\ S. V. TynChenko ${ }^{1,2}$, R. B. SergienKo ${ }^{5}$, A. S. MikhaleV ${ }^{1}$, I. A. PANFilov ${ }^{1,2,4}$ \\ ${ }^{1}$ Siberian Federal University, \\ 660041, Krasnoyarsk, \\ RUSSIA \\ ${ }^{2}$ Reshetnev Siberian State University of Science and Technology, \\ 660037, Krasnoyarsk, \\ RUSSIA \\ ${ }^{3}$ The branch of JSC FGC UES Krasnoyarsk enterprise MES Siberia, \\ 105/5, Pogranichnikov St., Krasnoyarsk, 660111, \\ RUSSIA \\ ${ }^{4}$ Krasnoyarsk State Agrarian University, \\ 90, Mira Ave., 660049, Krasnoyarsk, \\ RUSSIA \\ ${ }^{5}$ Gini Gmbh, \\ 80339, Munich, \\ GERMANY
}

\begin{abstract}
This article is dedicated to an important problem of increasing the reliability of supporting-rod porcelain insulation at electric power substations. Porcelain insulation is installed on open switchgears (OSGs) of substations as part of the main switching equipment. Obsolescence and physical wear results in the destruction of supporting-rod porcelain insulators (SRIs), which often leads to serious consequences: shutdown of substation bus systems, emergency shutdown of substation equipment, reduction of power plant loads, as well as they pose a threat to operational personnel during operational switching. When supporting-rod insulation is replaced in due time, it significantly increases the reliability of the main substation equipment. Possible causes of failures were analysed using a graphical technique (Ishikawa diagrams). It has been established that sudden temperature changes of the ambient air are an important negative aspect, especially the

transition of temperature values through $0^{\circ} \mathrm{C}$. The work represents a mathematical model of the development of microfractures in the insulation body of a ceramic insulator. The influence of external forces on the insulator leads to the appearance of additional stresses in it, to the destruction of new particles and to the sudden growth of microfractures. The article gives main SRI diagnostic techniques currently used in the electric power industry. According to statistics, it has been established that a relevant approach is the transition to digital technologies, which provides an automated information processing process without deactivating a piece of equipment. The article describes and proves that the proposed system of diagnostics of supporting-rod porcelain insulation at digital substations without deactivating a piece of equipment is a relevant area of scientific development. Within the framework of this scientific study, a patent for invention No. 2743887 dated 20 April 2020 was obtained.
\end{abstract}

Keywords: supporting-rod porcelain insulation, diagnostic system, failures, reliability, digital substations, ceramic insulator, reliability, SCADA.

Received: February 2, 2021. Revised: August 20, 2021. Accepted: August 27, 2021. Published September 3, 2021. 


\section{Introduction}

The reliability of power equipment that has reached the end of its service life is quite a relevant problem since it is difficult to replenish an enterprise's fleet with new equipment in addition to cost optimisation [1, 22-23]. The causes of failures and accidents of power equipment at transformer and traction substations are certainly obsolescence and physical wear [2-3].

An important factor that determines the operational efficiency of power equipment is its real condition. To date, most of the main power equipment has reached the end of its established fleet life or service life determined in the GOST standard. The analysis of the technical condition of electrical equipment of the Unified National Electric Grid (ENEG) shows that the degree of wear of fixed assets is on average 62\% (in the grids of PAO FGC UES-48.5\%). Moreover, the degree of wear of substation equipment reaches $73 \%$ (in PAO FGC UES-70\%), of buildings and structures-58\% (in PAO FGC UES-37.8\%), of power lines in PAO FGC UES-40\%. The highest degree of wear is observed in substation equipment. The following devices have reached the end of their service life: $19.7 \%$ of auto-transformers, $10 \%$ of shunt reactors, $20 \%$ of synchronous compensators, $27 \%$ of switches $(330-750 \mathrm{kV})$, more than $50 \%$ of relay protection and automation devices [24]. In grid distribution companies, equipment wear reaches $60 \%$.

The depreciation of fixed assets is one of the most important problems for electric grid companies. Its solution should be set on the path of finding a compromise between extending the life of existing equipment (repairs) and its modernisation, reconstruction, replacement, etc.

With limited investment resources, the determination of effective equipment service life is of special relevance since the increase in the volume of electric grid equipment that has reached the end of its service life exceeds the rates of its replacement with new pieces. Currently, there has been developed modern equipment that surpasses the existing one in terms of technical characteristics, weight-size parameters and reliability indicators. Therefore, the cost of repairing existing equipment is often comparable to that of new pieces. A very important point in solving the problem of replacing equipment is the choice of manufacturers since the cost / further operation expenses ratio may vary significantly. Currently, most manufacturers provide minimal information regarding their equipment. These are mainly technical characteristics and standard service life that, being a very important parameter, should be defined as an economically viable period of operation.

However, equipment manufacturers do not provide information on how the standard service life is determined and therefore cannot guarantee the validity of this parameter. Information on how to determine the reliability of equipment as its technical characteristic may also be unavailable to customers.

Therefore, the problem of replacing equipment is complicated by the fact that electric grid companies have very little information about new equipment when they take a decision [4-6].

The rationale for studying this problem is determined by the Government Decree Scientific and Technological Development of the Russian Federation (RF) for 2018-2025 dated 27 October 2017 that deals with a transition of the Russian Federation to advanced digital, intelligent production technologies, robot systems, new materials and design methods, to the creation of systems for processing large amounts of data, machine learning and artificial intelligence [7], as well as by the Regulation of PAO Rosseti On a Unified Technical Policy in the Electric Grid Industry. For the future, the following technological priorities of PAO Rosseti [8] have been established as the main areas of development:

- Use of "maintenance-free" energyefficient equipment;

- Reduction of the total cost of ownership of equipment and technologies in use;

- Construction of an intelligent energy system with an active-adaptive grid (Smart Grid);

- Introduction of "digital" power grid elements;

- Development of multi-agent control technologies;

- Use of "active" grid elements (FACTS, NEA, etc.).

The purpose of this work is to improve the reliability of equipment operation by optimising technological processes, reducing the time of failure detection, diagnostics and information about failures, reducing the time of equipment downtime after emergency shutdowns and repairs.

\section{Scientific novelty:}

1. There has been developed an automated SRI diagnostic technique that increases the reliability and cost-effectiveness of equipment operation by optimising technological processes, 
reducing the time of failure detection, providing diagnostics and information about failures, reducing the time of equipment downtime after emergency shutdowns and repairs. The diagnostics of the technical condition of supporting-rod porcelain insulation shows the condition of SRIs in real time, which helps to prevent damage and increase the reliability of both the electric power plant and the power system in general.

2. The diagnostics of the technical condition of supporting-rod porcelain insulators is carried out in a consistent manner and after each change of the breaker position.

3. Improvement of the working conditions and workforce productivity of operational personnel due to the increased awareness of technological processes and equipment operation, the quality of creation and analysis of operational documents.

Comparison of technical and economic indicators to foreign analogs: technical and economic indicators of the developed technique have been compared to foreign analogs. In the process of writing, we found the document US 20110101989 A1, published on 5 May 2011, 42 pages, Systems and Methods for Testing the Standoff Capability of an Overhead Power Transmission Line. The document shows a method and a system for detecting the breakdown of supporting insulators of a power transmission line. A similar work does not present the following aspects: 1 . A set of aspects defined as "affecting the insulator using a vibration exciter and the evaluation of a response signal of the insulator that registers spectral density and its comparison by level to the peak of the basic tone". 2. An automated workstation (AWS) of the power substation personnel, in particular an AWS with self-tuning training elements of the SCADA system (the description of a similar work gives information on data control and management by grid operators in supervisory control and data acquisition systems (SCADA), but there is no direct indication of AWSs).

\section{Analysis of the Causes of Failures of Supporting-Rod Insulators}

To determine the causes of failures of supporting-rod insulators, we use a visual graphical technique (Ishikawa diagrams). This diagram helps to identify main factors that have the greatest impact on the development of the problem under consideration, as well as to prevent or eliminate the effect of these factors.
Figure 1 shows the most common types of damages to porcelain insulators.
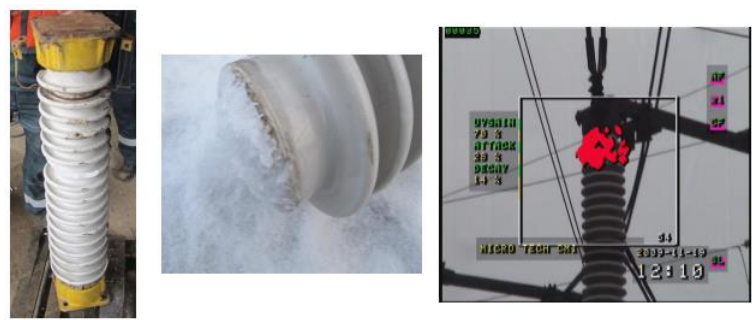

Figure 1. Types of damages to porcelain insulators

Figure 2 shows possible causes of SRI failures based on the graphical technique (Ishikawa diagrams).

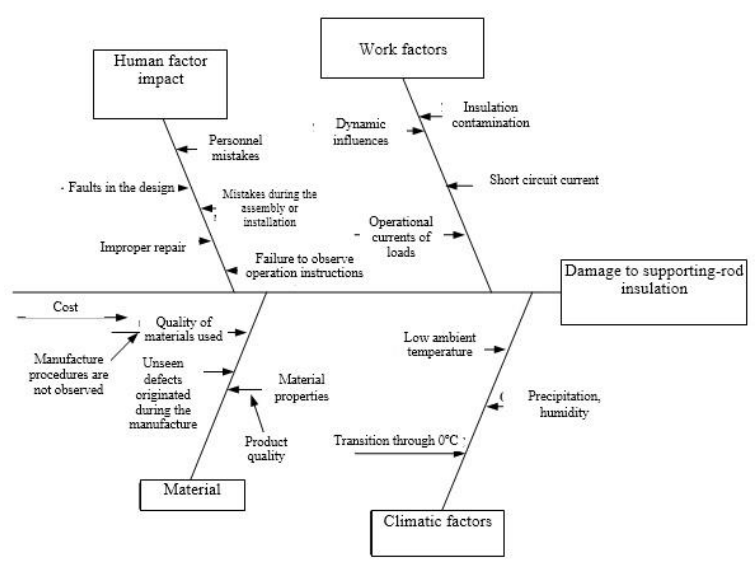

Figure 2. The Ishikawa diagram with possible causes of SRI damage

Sudden temperature changes, especially the transition of temperature values through $0^{\circ} \mathrm{C}$, affect supporting-rod porcelain insulation in a negative way [9].

This problem of sudden temperature changes is of special relevance for Siberia and the northern regions of Krasnoyarsk Krai.

As an example, Table 1 shows the temperature change values in Krasnoyarsk.

Table 1. Temperature change values in Krasnoyarsk

\begin{tabular}{lccccc}
\hline Month & $\begin{array}{c}\text { Absolut } \\
\mathrm{e} \\
\text { minimu } \\
\mathrm{m}\end{array}$ & $\begin{array}{c}\text { Mean } \\
\text { minimu } \\
\mathrm{m}\end{array}$ & Mean & $\begin{array}{c}\text { Mean } \\
\text { maximu } \\
\mathrm{m}\end{array}$ & $\begin{array}{c}\text { Absolute } \\
\text { maximu } \\
\mathrm{m}\end{array}$ \\
\hline January & $\begin{array}{c}-52.8 \\
(1931)\end{array}$ & -19.2 & -15.5 & -11.4 & $\begin{array}{c}6.0 \\
(1979)\end{array}$ \\
Februar & -41.6 & -16.9 & -12.8 & -8.0 & $\begin{array}{c}8.5 \\
\text { y }\end{array}$ \\
$\begin{array}{lllll}\text { March } \\
\text { (2001) }\end{array}$ & -38.7 & & & & $(1978)$ \\
April & $(1978)$ & -10.1 & -5.7 & -0.2 & $\begin{array}{c}18.5 \\
(2017)\end{array}$ \\
& -25.7 & & & & 31.4 \\
\hline
\end{tabular}




\begin{tabular}{|c|c|c|c|c|c|}
\hline May & $\begin{array}{c}-11.2 \\
(2001)\end{array}$ & 4.7 & 10.4 & 17.1 & $\begin{array}{c}34.0 \\
(2004)\end{array}$ \\
\hline June & $\begin{array}{c}-3.6 \\
(1992)\end{array}$ & 10.3 & 15.9 & 22.4 & $\begin{array}{c}34.8 \\
(1969)\end{array}$ \\
\hline July & $\begin{array}{c}3.3 \\
(2018)\end{array}$ & 13.4 & 18.7 & 24.8 & $\begin{array}{c}36.4 \\
(2002)\end{array}$ \\
\hline August & $\begin{array}{c}-1.0 \\
(2014)\end{array}$ & 10.8 & 15.7 & 21.8 & $\begin{array}{c}35.1 \\
(1995)\end{array}$ \\
\hline $\begin{array}{l}\text { Septem } \\
\text { ber }\end{array}$ & $\begin{array}{c}-9.6 \\
(1977)\end{array}$ & 4.8 & 8.9 & 14.4 & $\begin{array}{c}31.3 \\
(1966)\end{array}$ \\
\hline October & $\begin{array}{c}-25.1 \\
(1914)\end{array}$ & -1.6 & 2.0 & 6.4 & $\begin{array}{c}24.5 \\
(1967)\end{array}$ \\
\hline $\begin{array}{l}\text { Novem } \\
\text { ber }\end{array}$ & $\begin{array}{c}-42.3 \\
(1952)\end{array}$ & -10.6 & -7.2 & -3.4 & $\begin{array}{c}13.6 \\
(1978)\end{array}$ \\
\hline $\begin{array}{l}\text { Decem } \\
\text { ber }\end{array}$ & $\begin{array}{c}-47.0 \\
(1929)\end{array}$ & -17.1 & -13.4 & -9.4 & $\begin{array}{c}8.6 \\
(1955)\end{array}$ \\
\hline Year & $\begin{array}{c}-52.8 \\
(1931)\end{array}$ & -2.8 & 1.6 & 6.9 & $\begin{array}{c}36.4 \\
(2002)\end{array}$ \\
\hline
\end{tabular}

The reliability of porcelain insulators is determined primarily by the quality of their porcelain bodies [10]. It is understood, however, that

- defects of even very small sizes (a $0.1 \mathrm{~mm}$ deep surface fracture located at the lower flange of an insulator can lead to its destruction);

- it is difficult to predict the time needed for the development of a fracture from its initial appearance to porcelain breaking (from seconds to several years);

- it is impossible to visually detect internal porcelain fractures (as well as those located under the insulator flange), and surface fractures are very difficult to identify.

The influence of external forces on the insulator leads to the appearance of additional stresses in it, to the destruction of new particles and to the sudden growth of microfractures. At the same time, acoustic emission (AE) signals will be emitted. It is important to note that $\mathrm{AE}$ signals are registered even in high-quality products during primary loading. In case of repeated loading, AE signals will not be present until the load exceeds the magnitude that has been reached during the first loading cycle, and until particles that are stronger than those destroyed during the first loading start fracturing (the Kaiser effect).

The Kaiser effect is not observed (i.e. AE is present in case of repeated loading) if the socalled "main fracture" (MF) grows in porcelain. The MF is characterised by the development even at a constant level of load. Therefore, there are two possible types of porcelain fractures: the first one is non-dangerous microfractures that die down at a constant level of load and the second one is MFs that develop at a constant and even slightly reduced load (Fig. 3).

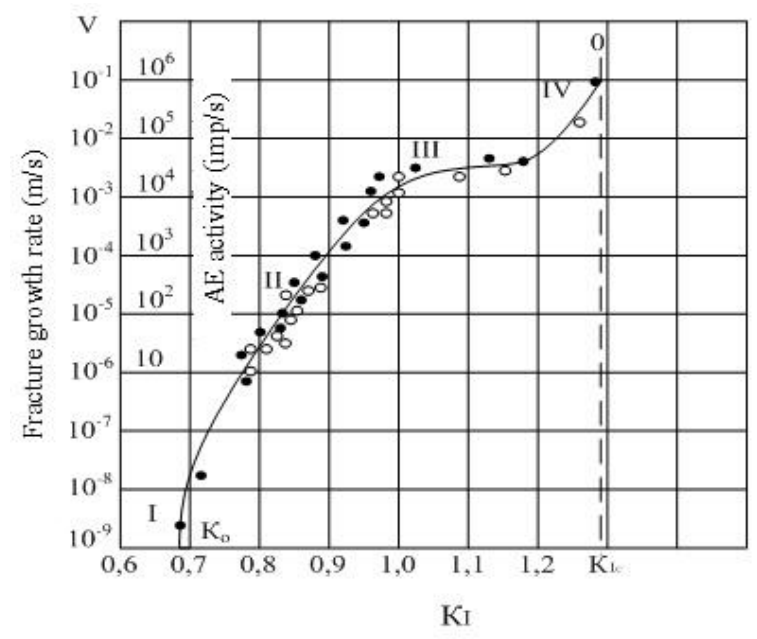

Figure 3. Dependence of the growth rate of the main fracture in ceramics and the acoustic emission activity on the stress intensity factor.

\section{Mathematical Model of the Development of Microfractures in the Insulation Body of a Ceramic Insulator}

Porcelain is known for the dependency shown in Figure 2. The MF growth rate on the stress intensity factor $\mathrm{K}_{\mathrm{I}}$ is proportional to the square root of the fracture length $\mathrm{L}$ and to the tensile stress:

$$
K i=A \cdot \sigma \cdot \sqrt{L},
$$

where $\mathrm{A}$ is a coefficient depending on the material properties.

If the fracture length and the applied stress are such that $K_{I}$ is less than the threshold intensity factor $K_{0}$, then the fracture will not develop $(\mathrm{V}=0)$, i.e. the product service life is unlimited. If $K_{I} \geq K_{0}$, then the fracture will grow at a rate according to Expression 2.

$$
V=\alpha \cdot K_{I_{i}}{ }^{n}=\beta \cdot\left(\frac{K_{I_{i}}}{K_{I_{C}}}\right) \text {, }
$$

where $\mathrm{n}$ is a parameter equal to $30-40$ for porcelain;

$\mathrm{K}_{\mathrm{Ic}}$ is a critical value of $\mathrm{K}_{\mathrm{I}}$ (in case of product breaking);

$\alpha$ and $\beta$ are coefficients depending on the material properties. 
The service life of a product with a MF, equal to the MF development time before the product breaking, can be found according to Formula 3.

$$
T=\frac{2 \cdot L}{(n-2) \cdot V}
$$

Since the index of degree $\mathrm{n}$ for porcelain is 30 40 , the product service life changes dramatically even with a small change in the $\mathrm{K}_{\mathrm{I}} / \mathrm{K}_{\mathrm{Ic}}$ ratio.

For example, Table 2 shows the $\mathrm{K}_{\mathrm{Ii}} / \mathrm{K}_{\mathrm{Ic}}$ magnitudes and the corresponding service life for one type of porcelain.

Table 2. The $\mathrm{K}_{\mathrm{Ii}} / \mathrm{K}_{\mathrm{Ic}}$ magnitudes and the corresponding service life

\begin{tabular}{lcccc}
\hline $\mathrm{K}_{\mathrm{Ii}} / \mathrm{K}_{\mathrm{Ic}}$ & 0.26 & 0.30 & 0.33 & 0.38 \\
\hline Period (T) & 20 years & 1 year & 1 month & 1 day \\
\hline
\end{tabular}

It is unacceptable to use a porcelain product with a MF since its service life is difficult to predict, and a slight increase in load leads to destruction. Therefore, insulators with MFs must be identified and rejected.

As mentioned before, an insulator with a MF can be identified when the Kaiser effect is not observed. Based on this effect, we have developed a control method that allows us to assess the condition of an insulator by the $\mathrm{AE}$ activity not during loading, but at a constant test load. There are two cycles of mechanical SRI loading up to a preset value of test load. At a constant value of test load, each cycle measures the AE activity. During the second measurement, the AE activity must be equal to zero in a high-quality product. If a MF develops in an insulator, then usually dozens, and sometimes hundreds, of AE pulses are registered during measurement.

It has been experimentally established that when an insulator without a MF is re-loaded, $\mathrm{AE}$ can occur at a load equal to the maximum load of the first cycle. This will cause a false rejection of the product. To avoid this, the first cycle must keep a constant maximum load for about 60 seconds and only then reduce it. In addition, the maximum load of the first cycle must be $7-10 \%$ more than that of the second cycle.

During AE control, an important methodological point is to correctly select a test load. It must simulate possible operational loads, and its value must be equal to or greater than the maximum operational load. If a $\mathrm{MF}$ is not identified in an insulator when these conditions are met, then it can be guaranteed that it will not develop in operation either.

It is know that breakers are equipped with such insulators, the minimum destructive load of which is 2.5 times more than the maximum operational load. Therefore, the test load must be equal to $40 \%$ of the minimum destructive load for this type of SRIs.

Once again, it should be noted that the specified test load does not exceed the standard design operational load and therefore cannot cause additional damage to high-quality SRIs.

Based on the above expressions, the relevance of diagnostics and timely replacement of supporting-rod porcelain insulation is due to a number of factors:

- Prevention of technological disturbances, which is the main reliability indicator in the electric power industry.

- Safety of substation maintenance personnel during operational switching.

There are many SRI diagnostic methods, such as: infrared thermography, insulation dielectric characteristics control, vibration diagnostics, electrophysical control, etc. [5, 1115].

The diagnostic method based on the use of vibration exciters and the evaluation of insulator response signals $[16,17]$ is promising in its technical essence.

The diagnostics of the technical condition of high-voltage supporting-rod porcelain insulators consists in estimating an insulator's response signal using a vibration exciter to affect the insulator. As a response signal, we register a vibration power spectral density (PSD) that occurs as a result of a vibration action when at least one additional peak comparable to that of a basic tone power spectral density is present or absent in the vibration power density spectrum. So it is further concluded whether the insulator is in satisfactory or unsatisfactory condition.

One of the disadvantages of this method is the absence of an automated SRI diagnostic process. Trained and experienced specialists must participate in the vibration assessment process.

\section{Technical Description and Results of Applying the Proposed Method}

Currently, a relevant approach is the transition to digital technologies, which provides an automated process for processing information 
received from vibration exciters without deactivating a piece of equipment (Fig. 4).

The developed automated diagnostic technique for the technical condition of supporting-rod insulation at digital substations is carried out as follows.

Accelerometer 2 and acoustic transmitter 3 are installed on supporting-rod porcelain insulator 1 (Fig. 4). A signal in the frequency range of $500 \mathrm{~Hz}-20 \mathrm{kHz}$ is fed to the transmitter using an acoustic generator (a "white noise" generator).

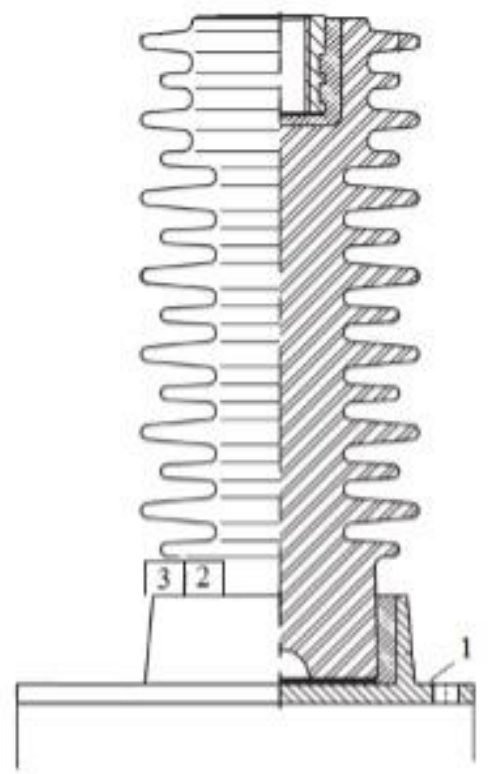

Figure 4. A supporting-rod porcelain insulator with an accelerometer and acoustic transmitter

Accelerometer 2 and acoustic transmitter 3 are installed on supporting-rod porcelain insulator 1 (Fig. 4). A signal in the frequency range of 500 $\mathrm{Hz}-20 \mathrm{kHz}$ is fed to the transmitter using an acoustic generator (a "white noise" generator).

The accelerometer records readings, processes the signal, as a result of which the insulator frequency behavior is obtained (Fig. 5). The data are transmitted to decision-making unit 4 , via optical fibre communication line 5 (OFCL) a signal is transmitted through the controller to switch 6 and then to automated workstation 7 (AWS) of the substation operational personnel by means of SCADA (Fig. 6, 7).

The data sampling set specified in [18] can be used as a decision-making unit.

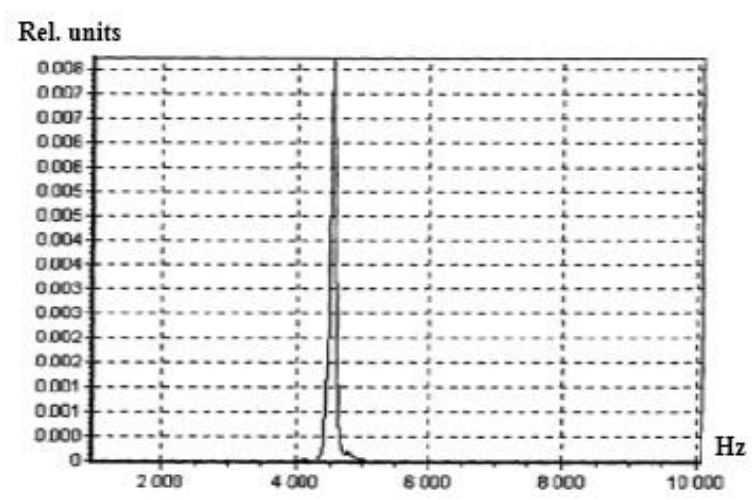

Figure 5. Frequency behavior of an insulator obtained by analysing the diagnostic method of supporting-rod insulation

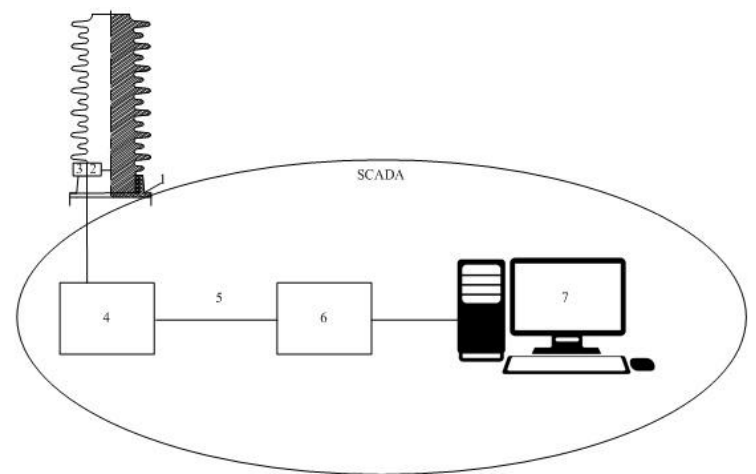

Figure 6. The developed diagnostics of the technical condition of supporting-rod porcelain insulation in the supervisory control and data acquisition system (SCADA)

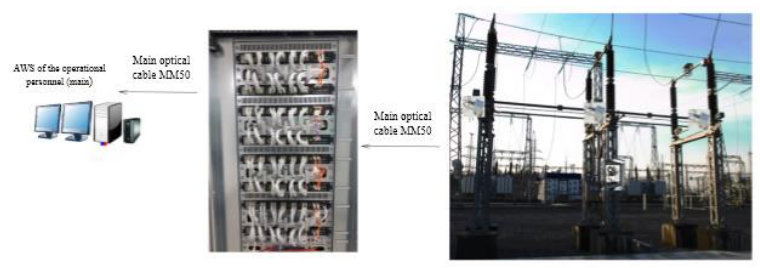

Figure 7. Diagnostics of the technical condition of supporting-rod porcelain insulation in the supervisory control and data acquisition system (SCADA)

The data sampling set using the VibroBox DVS1703 sensor [18] can be used as a decisionmaking unit.

Sources of vibration signals and other telemetry data transmit primary information to the decision-making unit with the VibroBox system. This system is responsible for processing incoming information, assessing the technical condition of equipment and generating instructions for its operation and maintenance.

Figure 8 shows the structure of the information processing system in the decisionmaking unit. 


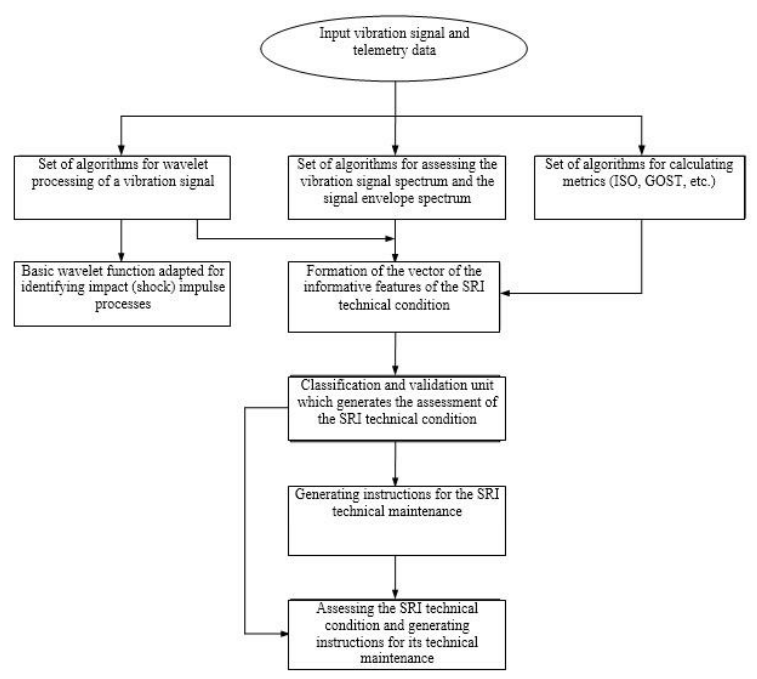

Figure 8. The structure of the VibroBox information processing system

The decision-making unit uses a method of analysing spectral components (analysis of the direct spectrum and the envelope spectrum of a vibration signal). Currently, this is the most popular method of forming the space of informative features as it lies at the core of modern vibration diagnostics systems). The main expressions of this method are the Fourier transform and the inverse Fourier transform, Expressions 4, 5.

$$
\begin{aligned}
& \hat{f}(\omega)=\int_{-\infty}^{+\infty}(t) \cdot e^{-i \cdot \omega \cdot t} d t \\
& f(t)=\frac{1}{2 \cdot \pi} \int_{-\infty}^{+\infty} \hat{f}(\omega) \cdot e^{i \cdot \omega \cdot t} d \omega
\end{aligned}
$$

The decision-making unit system contains a unit to calculate the spectrum (PSD) and the envelope spectrum of a vibration signal, and a number of typical vibration diagnostic maps are used to retrain classifiers. All informative features calculated from the spectrum and the envelope spectrum of a vibration signal participate in the formation of a general feature vector of the technical condition of equipment, according to which the classifier operates, based on fuzzy logic. Also, the system in use analyses the history of changing the spectrum of a vibration signal and the spectrum of its envelope in order to detect the dynamics of processes.

The diagnostics of the technical condition of SRIs takes place after each change of the position (switching by the breaker). A survey is started by SCADA.

The diagnostic system of the technical condition of supporting-rod porcelain insulators as part of the implementation of the Digital Substation concept is presented in Figure 9.

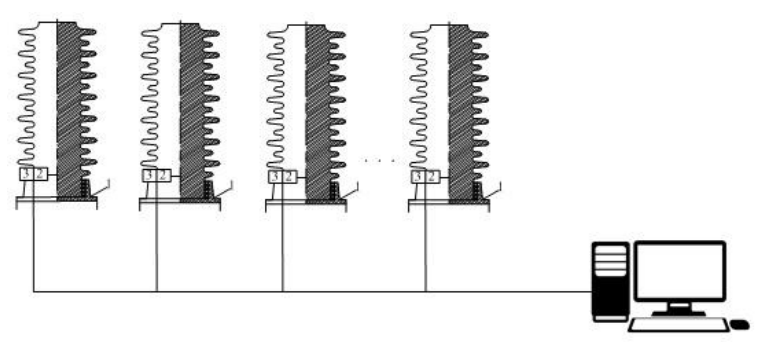

Figure 9. Diagnostics of the technical condition of supporting-rod porcelain insulators as part of the implementation of the Digital Substation concept

The most important parameters can be continuously monitored in real time using analyser sensors (IDAX206, an insulation parameter meter; AR700, a device for the location of insulation defects, etc.).

The diagnostic system of the technical condition of supporting-rod porcelain insulation at digital substations that includes affecting the insulator through a vibration exciter, the evaluation of the insulator's response signal, the registration of spectral density and the measurement of its level with the peak of the basic tone is of interest because a signal on the condition of each supporting porcelain insulator

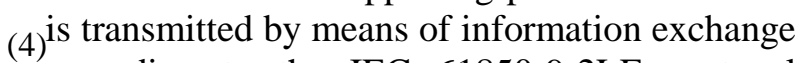
according to the IEC 61850-9-2LE protocol between microprocessor complexes at the AWS (5) of an electric power substation in real time (5) where a deviation from the readings of previous responses is estimated and the critical condition of each insulator is predicted over time, using the built-in self-tuning training element of the software system, as part of the SCADA system. The substation personnel can preset an increase or decrease in the time intervals for monitoring the condition of supporting insulators in order to predict their preventive replacement and reduce maintenance periods for SRIs that are quickly singled out into the critical replacement group.

According to the updated decreasing indicators of the critical condition of insulators, a decision is made by the senior operational personnel of an electric power industry facility regarding a critical insulator included in the replacement group in order to quickly optimise the supporting porcelain insulators at this substation.

Using the developed diagnostic system for the technical condition of support-rod porcelain insulation at digital substations, it becomes possible to ensure the safety of the substation 
maintenance personnel, both during operational switching and during scheduled inspections. There are known cases when the stack of a porcelain insulator drops during operational switchings carried out on the open part of PSs, such phenomenon is possible during a strong wind or a transition through 0 . The timely detection of defective insulators helps to prevent accidents with production personnel.

\section{Conclusions}

The problem of extending the SRI service life can be solved only if the condition of equipment is effectively controlled by continuously monitoring parameters that reflect the development of defects and failures, by surveys, including a detailed analysis of all possible parameters.

The diagnostics of the technical condition of supporting-rod porcelain insulation shows the condition of SRIs in real time, which helps to prevent damage and increase the reliability of both the electric power plant and the power system in general.

The transition to digital SRI diagnostics ensures the safety of the substation maintenance personnel, both during operational switching and during scheduled inspections.

Thanks to the automatic SRI control, it becomes possible to rationally use electric energy, as well as to identify "invisible" losses and non-production expenses.

The automated SRI diagnostic method reduces losses from equipment damage by preventing emergency situations.

\section{References:}

[1] Lukovenko, A. S., Khristinich, R. M. Improving the Reliability of Traction Power Supply Equipment of Electric Substations During Operation in Critical Modes, ELEKTRO, Electrical engineering, electric power industry, electrotechnical industry, No. 2, 2016, pp. 36-40.

[2] Bubenchikov, A. A., Nurakhmet, E. E., Molodykh, V. O., Rudenok, A. I. The Most Characteristic Failures in Power Equipment, International Research Journal, No. 5(47), 3, 2016, pp. 56-58.

[3] Valyansky, A. V., Kartashev, I. I., Sharov, Yu. V. The Impact of Power Quality on the Reliability of Power Transformers, Electrical engineering, No. 3, 2014, pp. 2027.

[4] Gayvoronsky, A. S., Damage of polymer insulators and their diagnostics during operation, Chief Power Engineer, No. 2, 2010, pp. 23-27.

[5] Vorotnitsky, V. E., Dmitriev, I. N., Mlotok, A. V., Demin A. N. Diagnostics of the Mechanical Condition of Supporting-Rod Porcelain Insulation of High-Voltage Breakers in Operation, Energy of the Single Grid, No. 2(13), 2014, pp. 4-14.

[6] The Main Power Networks of Siberia Replace Supporting-Rod Insulation at the 220-1150 kV Substations, Internet newspaper Newslab, http://newslab.ru/news/284791.

[7] The State Program of the Russian Federation: Scientific and Technological Development of the Russian Federation. Passport of the State Program of the Russian Federation, the Scientific and Technological Development of the Russian Federation for 2018-2025. Moscow, 2017, 127.

[8] The Regulation of PAO Rosseti On a Unified Technical Policy in the Electric Grid Industry, the official website of PAO Rosseti, http://www.rosseti.ru/investment/science/te $\mathrm{ch} /$ doc/tehpolitika.pdf.

[9] The Main Power Networks of Siberia Replace Supporting-Rod Insulation at the 220-1150 kV Substations, Internet newspaper Newslab, http://newslab.ru/news/284791.

[10] Methodical Instructions for Controling the Mechanical Condition of $110 \mathrm{kV}$ and Above Porcelain Supporting-Rod Insulators and Porcelain Covers of High-Voltage Overhead and Oil Switches in Operation, agreed upon with OAO FGC UES, approved by OAO RAO UES, 30 December 2004, 61.

[11] Vorotnitsky, V. E. et al., Diagnostics of the Mechanical Condition of Supporting-Rod Porcelain Insulation of High-Voltage Breakers in Operation, Energy of the Single Grid, No. 2(1), 2014, pp. 4-14.

[12] Turzhin, A. V., Methods of the Efficient Technical Diagnostics of Equipment. Ultrasonic Control PS 35-110 kV, Electric Energy. Transmission and Distribution, No. 3(42), 2017, pp. 120-123.

[13] Methodological Guidelines for the Remote Optical Control of Insulation of Overhead Power Transmission Lines and AC Switchgears (35-1150 kV). STO 56947007 29.240.003-2008, http://www.fsk-ees.ru

[14] Emelyanov, V. I., Petrov, O. E., A Diagnostic Technique for the Technical 
Condition of a High-Voltage SupportingRod Porcelain Insulator. Pat. No. RUS 2275647, IPC G01R 31/00, Appl. No. 2003120314/28, Publ. on 27 April 2006.

[15] Gataullin, A. M. et al., The Vibration Control of the Mechanical Condition of Supporting-Rod Porcelain Insulators by Sonic and Low-Frequency Ultrasonic Methods, Energy Problems, No.1-2, 2008, pp. 112-118.

[16] The Technology of Automatic Preventive Maintenance of Industrial Equipment, https://www.vibrobox.ru/technology/.

[17] Lukovenko, A. S., An Automated Diagnostic Technique for the Technical Condition of Supporting-Rod Insulation at Digital Substations. Pat. No. RUS 2743887 , IPC G01R 31/00. App. No. 2020116008, Publ. on 1 March 2021.

\section{Creative Commons Attribution License 4.0} (Attribution 4.0 International, CC BY 4.0)

This article is published under the terms of the Creative Commons Attribution License 4.0

https://creativecommons.org/licenses/by/4.0/deed.en_US 